\title{
Jó nos primeiros anos do cristianismo: referências em Clemente de Roma e em Justino mártir
}

\author{
Job in the first years of Christianity: \\ quotations from Clement of Rome and Justin Martyr
}

\section{Resumo}

Este estudo preza pelo entendimento primitivo que os cristãos formularam a partir da leitura dos textos do Antigo Testamento, com especial atenção à primeira interpretação patrística sobre o livro de Jó. Para cumprir tal objetivo, as obras de Clemente de Roma e de Justino Mártir são analisadas, enquanto esses foram os únicos escritores do primeiro e do segundo século a mencionálo como exemplo de virtude e a se ocupar com comentários sobre o texto. A análise em Clemente permite encontrar sinais de reconhecimento e renome entre os cristãos, introduz a utilidade da humildade a partir do exemplo de Jó e antecipa a figura da fênix como testemunho da ressurreição. Embora o número de citações em Justino seja consideravelmente menor do que em Clemente, delineia-se com precisão os elementos da cristologia angélica a partir de uma versão própria de Jó 1,6, aplicada a momentos especiais da vida de Cristo.

Palavras-chave: Clemente de Roma. Justino. Jó. Fênix. Anjo. Cristologia.

\section{Abstract}

This research aims to investigate the earliest Christian commentaries on texts of the Old Testament, focusing on Job's first interpretation among the Fathers of the Church. Therefore, the letter of Saint Clement of Rome 
to the Corinthians and the books of Saint Justin Martyr have been selected to be analyzed, given that both writers were the only ones who mentioned Job as a portraying of virtue and quoted some verses from the book of Job in the first and second centuries. Clement testifies that the spreading of the book of Job is figured out across Christian communities at the end of the first century, germinates the necessity of humbleness from the example of Job, and announces the Phoenix's depiction as a testimony of the resurrection. Despite the fact that Justin's books were not larded with so many literary quotations as Clement's, Justin is able to herald new elements to the angelical Christology, favoring the Christian hermeneutics with a new version of Job 1:6 and setting the scene of the celestial court for the beginning of Jesus' mission.

Keywords: Clement of Rome. Justin. Job. Phoenix. Angel. Christology.

\section{Introdução}

Os primeiros sinais da literatura cristã pós-testamentária incluem os assim classificados Padres Apostólicos e Padres Apologistas. As primeiras gerações que surgiram depois dos apóstolos de Cristo, tiveram que entender a forma como deviam processar as informações do Antigo Testamento com os ensinamentos de Cristo. Explorar qualquer citação do Antigo Testamento nos textos patrísticos requer a reconstrução daquele contexto, em que as tradições orais com pouco mais de um século começavam a ser confrontadas com a autoridade textual das Escrituras, com o objetivo de fortalecer as bases morais e religiosas da comunidade cristã. A explicação da fé está em construção e em processo de esclarecimento, assim como a busca de parâmetros novos para a práxis evangélica. A versão egípcia das Escrituras, ou seja, a versão dos LXX ganha credibilidade em centros metropolitanos importantes, ocupando um espaço de proeminência e espalhando as doutrinas do modo que lhe eram pertinentes. As perseguições impõem novas questões que precisam ser respondidas, para que o fiel se esforce de modo concreto para encontrar a perfeição. Nesse estudo, analisamos os textos de Clemente de Roma e Justino Mártir, esperando reconstruir o primeiro painel literário sobre o uso do Livro de Jó nos primeiros anos do Cristianismo. 


\section{O justo e a fênix em Clemente de Roma}

Ora, é Clemente o responsável por trazer para o cenário patrístico a primeira e mais antiga referência ao livro de Jó, cuja menção explícita e literal não aparece entre os Padres Apostólicos, senão quando esse mesmo escreve para os irmãos de Corinto, para aconselhar que os seus líderes não sejam destituídos da frente daquela comunidade. Ao fazer isso, o bispo romano se interessa, da literatura paulina destinada àquela comunidade, em recuperar tanto os motivos dos conflitos que havia décadas contribuíam para a divisão dos seus membros, quanto alguns temas teológicos abordados pelo Apóstolo. Coincidentemente, um breve texto de Jó também foi citado por Paulo em 1Cor 3,19 , onde se diz que "Ele apanha os sábios em sua própria astúcia" (Jó 5, 13)1 em refrega contra aquela soberba pela qual os partidos tinham se formado pela primeira vez.

Na condição de líder da comunidade cristã de Roma, para a igreja de Deus que habitava Corinto ${ }^{2}$ Clemente escreve como conselheiro ${ }^{3}$ que tenta promover a concórdia, depois de ter ouvido que os membros mais jovens tinham se rebelado contra os anciãos. ${ }^{4} \mathrm{~A}$ análise da conjuntura, feita por quem de longe está vendo se espalhar o rumor sobre o confronto, é clara: assim como no tempo de Paulo a soberba e a vaidade tinham tomado o coração daqueles que promoviam a discórdia eclesial. É necessário que esses se arrependam, buscando os exemplos de humildade apresentados pelas Escrituras. Temos, então, a primeira indicação de Jó, que é apresentado entre Elias, Eliseu, Abraão, Moisés e Davi, por causa do seu comportamento diante da vida, ou seja, como quem não se deixa levar pela arrogância e pelo orgulho. ${ }^{5} \mathrm{Na}$ verdade, a arte e a cultura cristã ressaltaram a posição de Jó a partir do paradigma que Clemente Romano está introduzindo. Cunha-se a imagem de Jó como

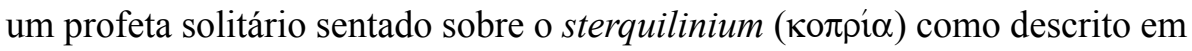
Jó 2,8. ${ }^{6} \mathrm{~A}$ iconografia o descreve sentado sobre os cacos de cerâmica, sobre as cinzas ou sobre pedras. $\mathrm{O}$ destaque que recebeu nos meados do quarto século entre as estruturas do precioso e detalhado sarcófago de Júlio Basso,

\footnotetext{
${ }^{1}$ PORTER, S. E.; LAND, C. D., Paul and Scripture, p. 367.

${ }^{2}$ CLEMENT of Rome, 1Clem. 1,1.

${ }^{3}$ CLEMENT of Rome, 1Clem. 58,2.

${ }^{4}$ CLEMENT of Rome, 1Clem. 47,6.

${ }^{5}$ CLEMENT of Rome, 1Clem. 17,1-18,17.

${ }^{6}$ CARNEVALE, L., Giobbe, p. 104-105.
} 
ocupando a primeira cena à esquerda da faixa inferior da escultura, consagra a importância que este modelo adquiriu entre os cristãos dos primeiros séculos. Esta referência se torna vastamente comum entre as catacumbas romanas. ${ }^{7}$ Quem a vê, entende o apelo penitencial, mas também é capaz de se perguntar por qual motivo exatamente aquele personagem tenha sido levado a se sentar sobre o lixo.

Para Clemente, ninguém mais que Jó com os seus amigos - isto é, com os demais profetas que foram humilhados - pode responder ao drama do homem justo destinado a ser rebaixado pelas vicissitudes da própria vida, uma vez que a sua dor o une a Cristo que tinha humilhado a si mesmo. ${ }^{8}$ Estão todos debaixo do mesmo jugo de sua graça, por isso, cita Jó 14,4-5: Ninguém é puro, se sai do lixo, mesmo que a sua vida seja de apenas um dia

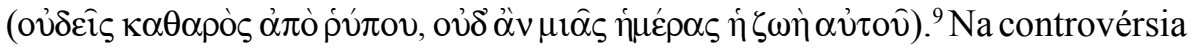
sobre o batismo das crianças, no quinto século, a interpretação deste texto provocará tensão entre aqueles que supervalorizam a condição do justo como homem perfeito, defendendo a autonomia do homem em demérito da graça de Deus, e aqueles que demonstram que mesmo os recém-nascidos não podem se valer dos próprios méritos para a sua salvação, apoiando a utilidade da humildade para todos os que já tiverem alcançado aquela pureza desejada ou vivem aquela inocência admirada nos pequeninos. ${ }^{10}$ Segundo Joseph Ziegler, em consequência da extensa divulgação de Jó 14,4-5 a interpretação destes versículos em ambiente cristão deve ser considerada a maior responsável pela demonstração do conceito universal pelo qual o pecado é uma realidade para toda a humanidade. ${ }^{11}$ Por outro lado, para os membros da comunidade de Corinto voltarem à perfeição este é o caminho alternativo, pelo qual não se perdem na própria soberba, pois Jó, antes de ter vivido tais sofrimentos, segundo Jó 1,1 , já era justo, sem culpa, verdadeiro, piedoso e evitava o mal. ${ }^{12}$ Qualquer iniciativa que tomarem os jovens membros da comunidade de Corinto para corrigir o que eventualmente consideram injusto ou errado perde significado quando esses se deixam levar pelo orgulho.

Com a imagem de Jó e os seus amigos, Clemente pode nos ajudar a

\footnotetext{
${ }^{7}$ CARNEVALE, L., Giobbe, p. 177-180.

${ }^{8}$ CLEMENT of Rome, 1Clem. 16,17.

${ }^{9}$ CLEMENT of Rome, 1Clem. 17,4.

${ }^{10}$ AGOSTINO, De perf. iust. 11,23.

${ }^{11}$ ZIEGLER, J., Iob 14,4-5a, p.17.

${ }^{12}$ CLEMENT of Rome, 1Clem. 17,3.
} 
desvendar um dos maiores mistérios sobre o destino do livro sapiencial dentro da primeira literatura cristã. Diz-se que nas obras dos Padres dos primeiros dois séculos a figura de Jó e, em decorrência, o pensamento retirado do livro como o seu nome são praticamente ausentes, a despeito do levantamento de referências que fazemos nesse estudo. Acreditamos ter trazido mais detalhes que a professora Mara, ${ }^{13}$ que faz apenas uma única citação para concluir sobre a ausência de Jó nos primeiros dois séculos. Isso não quer dizer, todavia, que a sua conclusão seja inapropriada nem tampouco que tenha que ser substituída. A exiguidade de citações do livro de Jó sempre deixou dúvidas para os estudiosos da Antiguidade Cristã. ${ }^{14}$ No entanto, Clemente garante que Jó, assim como Elias, Eliseu, Abraão, Moisés e Davi, é $\mu \varepsilon \mu \alpha \rho \tau v \rho \eta \mu \varepsilon ́ v o \varsigma,{ }^{15}$ isto é, utiliza algumas vezes este termo para atestar que Jó seja renomado, no nível de Moisés, por exemplo.

Em primeiro lugar, a ausência de citações explícitas de um livro da Bíblia na Literatura Patrística jamais poderá ser lida como um índice pleno de desconfiança sobre a utilização escriturística entre os cristãos, como se esses rejeitassem, desconsiderassem ou até mesmo desconhecessem aquela obra. Essa norma se aplica, por exemplo, ao Cântico dos Cânticos do Antigo Testamento e ao evangelho de são João do Novo Testamento. Em segundo lugar, é inadmissível que os cristãos não recorressem ao exemplo de Jó sobretudo no período das grandes perseguições, já que o modelo do justo perseguido injustamente era respaldado nas Escrituras Sagradas para fortalecê-los na luta pelo testemunho da verdade e pela propagação do Evangelho. Em terceiro lugar, não se pode esquecer que os dois primeiros séculos sejam o troféu da literatura cristã marcada pela espiritualidade do martírio, em que a superação do sofrimento e da morte, assim como descrito pelo dramático percurso de Jó até encontrar a sua consolação em Deus, é uma constante em todos os textos dos primeiros Padres da Igreja. Em quarto lugar, não faltaram tensões em que o uso de todos os livros do Antigo Testamento começou a ser questionado, sobretudo por Marcião, a ponto de inibir, pelo menos em contexto romano, a leitura veterotestamentária. Enfim, sabemos que nem tudo o que foi produzido chegou aténós. Pelo contrário, muito pouco da literatura cristã antiga sobreviveu até os nossos dias. Os textos patrísticos que sobreviveram se tornaram uma porta de acesso a um contexto que, aos poucos, tem sido desbravado para

${ }^{13}$ MARA, M. G., Giobbe, p. 2158-2159.

${ }^{14}$ CARNEVALE, L., Giobbe, p. 56.

${ }^{15}$ CLEMENT of Rome, 1Clem. 17,1;17,2;19,1. 
além dos limites literários. O conjunto desses fatores contribuiu para que a ausência de citações sobre Jó se concretizasse na literatura patrística até a recuperação do mesmo pela escola alexandrina. Em última análise, a voz de Clemente de Roma permanece a mais importante para entender que o livro de Jó alcançara a esfera de grande renome não apenas para os cristãos contemporâneos ao bispo romano mas também para a geração precedente

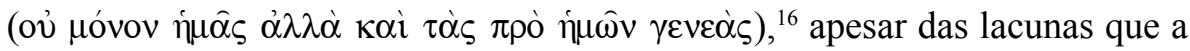
produção literária criou.

O tema da ressureição como o ciclo da árvore cujo fruto amadurece depois de ter perdido as suas folhas ${ }^{17}$ é introduzido na carta de Clemente aos Coríntios, quando o bispo romano assemelha Cristo, seguido dos que servem a Deus, como aquele fruto que o Mestre do Universo, ou seja, o Pai, foi capaz

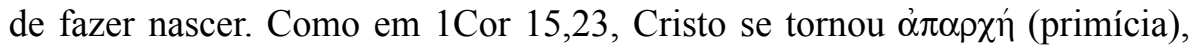
quando o Pai o fez ressurgir da morte. ${ }^{18}$ Cristo revela o poder do Pai sobre toda criação, deixando nela os sinais daquilo que fará com os que também se humilham: enquanto o impávido mar é dominado pelo poder divino - aqui uma breve citação de Jó 38,11 - o dia aparece, quando a noite cai; a noite retorna, quando o dia termina; a semente morre, depois de ser semeada, mas germina pela providência divina. $\mathrm{O}$ sinal mais extraordinário que a natureza podia ter manifestado sobre o poder de Deus e a ressurreição é o de uma ave de quinhentos anos, proveniente das regiões da Arábia. Com ela, Clemente retira do livro de Jó o testemunho de como os cristãos estavam construindo as bases iniciais da cristologia. Segundo Joseph Nigg, esta proposta de Clemente permite que Roma formule um conceito cristológico duradouro, com efeitos sobre a literatura, como no caso de Ambrósio e de Isidoro, sobre a arte, em especial nos afrescos da Catacumba de Priscilla e no mosaico da Basílica dos santos Cosme e Damião, e sobre o tempo, tornando-se seminal para autores medievais. ${ }^{19}$ Não precisamos sair do primeiro século da era cristã para verificar como as tradições helênicas, hebraicas e cristãs eram harmonicamente equacionadas em função da ordem pastoral de levar o ensinamento de Cristo a todos os povos. ${ }^{20}$ No entanto, a forma mais adequada de se entender este processo de sincretismo cultural será observando Clemente como representante

\footnotetext{
${ }^{16}$ CLEMENT of Rome, 1Clem. 19,1.

${ }^{17}$ CLEMENT of Rome, 1Clem. 23,4.

${ }^{18}$ CLEMENT of Rome, 1Clem. 24,2-3.

${ }^{19}$ NIGG, J., Transformation of the Phoenix, p. 96.

${ }^{20}$ NIGG, J., Transformation of the Phoenix, p. 95.
} 
apenas do Cristianismo romano, sem que precisemos esboçar conclusões equivocadas que pretendam amadurecer precocemente os componentes do desenvolvimento dogmático e sem pretender que o judaísmo e a cultura pagã transmitissem na mesma medida aquilo que se tornava coincidente por causa das tradições comuns.

Clemente afirma que o pássaro da Arábia é chamado de $\phi o i ̂ v ı,,^{21}$ intuindo, na conclusão dessa parte da carta, que em três breves citações dos textos sapienciais ele pode encontrar a explicação para aquele animal. $\mathrm{Na}$ verdade, enquanto é acurado ao citar os Salmos e o livro de Jó para definir a sua hermenêutica, resvala no tocante às citações de todos os três textos, não se aproximando literalmente daquele lugar comum em que os autores cristãos conseguiam encontrar o pássaro nas Sagradas Escrituras, mas resgata para todos os três textos o valor conceitual que os cristãos retiravam do texto de Jó, como explicitaremos mais adiante. Antes de passar para os textos, insistimos sobre essa nossa constatação, pois tal insegurança pode nos alertar que Clemente não esteja criando ex novo a sua hermenêutica sobre o pássaro da ressurreição, mas encontre em tradições anteriores - aproximadamente de 30 a 100 a.D., se as considerarmos em perspectivas embrionárias cristãs aqueles significados que pretende construir. Hervé Tremblay também aceita que esse tipo de hermenêutica precisa ser mais antiga que Clemente. ${ }^{22} \mathrm{O}$ justo posicionamento sobre essas informações nos é dado pelo magistral professor Manlio Simonetti, ao argumentar que:

O ambiente da literatura exegética deve ser considerado, no que diz respeito aos nossos conhecimentos atuais, somente como a ponta de um grande iceberg representado pela atividade exegética desenvolvida pela comunicação oral, sobretudo através da pregação homilética. Somente se tal constatação for considerada - só aparentemente óbvia - seremos capazes de aprofundar a pesquisa sobre esta matéria colocando-a sobre uma firme plataforma metodológica, que até no dia de hoje não aparece ainda plenamente realizada. ${ }^{23}$

A Basílica dos santos mártires Cosme e Damião foi decorada no período do Papa Félix IV, no sexto século, em função da dedicação de antigas

${ }^{21}$ CLEMENT of Rome, 1Clem. 24,2-3.

22 TREMBLAY, H., Job 19,25-27 dans la Septante, p. 292.

${ }^{23}$ SIMONETTI, M., Il cristianesimo antico, p. 13. 
edificações do Foro Romano que deram lugar para o novo templo. O tema central da decoração era aquele da traditio legis que vinha se desenvolvendo na arte romana desde os primeiros séculos. Uma das novidades era a inserção da fênix nas palmas da árvore que representava a ecclesia ex gentibus, determinada pela pregação paulina. ${ }^{24}$ As palmas e a fênix são temas que se cruzaram no imaginário cristão desde as origens. Segundo a versão da

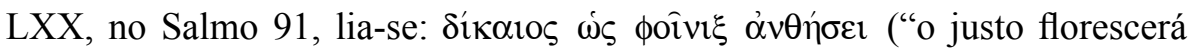
como a palmeira”, Sal 91(92),13), enquanto o texto de Jó era assim citado:

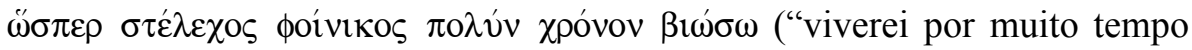
como o tronco da palmeira", Jó 29, 18). A ambiguidade da segunda citação favoreceu a confusão pela qual este texto de Jó também começou a ser traduzido como "viverei por muito tempo como o tronco da fênix". Estes temas se aprofundaram ainda mais, quando Jerônimo decidiu traduzir a Vulgata diretamente do texto em hebraico, propondo o versículo nos seguintes termos: "in nidulo meo moriar et sicut palma multiplicabo dies" ("no meu ninho morrerei e assim como a palmeira multiplicarei os dias"). O ninho no qual se morre já tinha se tornado uma alusão direta à ave fênix.

Os comentários que são transmitidos por Clemente Romano falam, então,

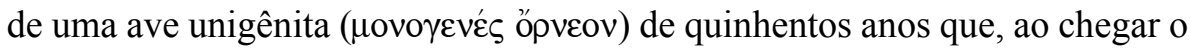
tempo da sua morte, prepara para si um ninho (бүкó $)$ ) feito da mistura entre incenso, mirra e plantas aromáticas, onde se posiciona numa espécie de casulo para sofrer a mutação: da sua carne, então, em decomposição surge uma larva que cria asas por nutrir-se do próprio chorume. Em seguida, ao recuperar as suas forças, a fênix voa da Arábia para o Egito para depositar o ninho, com o que restou do seu corpo, sobre o altar do sol para, em seguida, voltar par a Arábia. $^{25}$

Após o comentário, Clemente cita os breves textos, como tínhamos antecipado: em primeiro lugar, dois trechos dos Salmos e, depois, um de Jó, com o intuito de respaldar a lenda da fênix com textos que prometem a ressurreição para todos quantos servem a Deus. De versões próprias do Salmo 28,7 ("tu me fazes levantar e eu hei de te louvar") e do Salmo 3,5 ("deitarei e durmo; hei de me levantar pois tu estás comigo") retira as mesmas soluções que a partir de Jó 19, 26 ("hás de levantar a minha carne que suportou todas essas coisas").

\footnotetext{
${ }^{24}$ BISHOP, W. W., Roman Church Mosaics, p. 263.

${ }^{25}$ CLEMENT of Rome, 1Clem. 25,2-5.
} 
Em conclusão, o limite pastoral imposto pela necessidade de interferir como conselheiro na questão sobre a divisão da comunidade de Corinto leva Clemente a encontrar saídas teológicas que respeitem tal limite, de modo que não aumente ainda mais a tensão que ocorria por ali. Nesse contexto, recorre à figura de Jó seja para que os jovens rebeldes verifiquem a sua postura soberba, seja para que esses confiem que, mantendo o serviço de forma humilde e a consequente unidade da comunidade, hão de receber as mesmas recompensas que Cristo recebeu, ou seja, a ressurreição. Mesmo o longo texto de Jó 5,17-26 citado por Clemente ${ }^{26}$ deve ser entendido a partir da correção à qual o justo é submetido para alcançar a bênção do Senhor. Secundariamente, Clemente acaba criando espaço bem fecundo para a futura e tradicional hermenêutica patrística que apoiava o dinamismo ascético a partir do modelo do justo injustamente perseguido, mas premiado por Deus por causa da sua perseverança, e para a cristologia que não encontrava mais embaraço em associar aquele redentor ( $\dot{o}$ $\dot{\varepsilon} \kappa \lambda \hat{\varepsilon} \iota v \mu \varepsilon \mu \dot{\varepsilon} \lambda \lambda \omega v$ - “aquele que deve me libertar") de Jó 19,25 com Jesus Cristo, vivo e ressuscitado. O desenvolvimento dos temas bíblicos sobre o ninho, sobre a palmeira e, sobretudo, sobre a fênix só aparecem na sucessiva literatura sob a perspectiva desses interesses teológicos.

\section{Os membros da corte celestial em Justino mártir}

Entre a morte de Clemente e a morte de Justino estão aproximadamente 65 anos de intenso desenvolvimento do cristianismo na cidade de Roma. Esses anos representam os mais importantes casos de sobrevivência daqueles textos que, ao lado dos escritos canônicos do Novo Testamento, se tornaram referências para se chegar à originalidade da fé cristã. Nesse intervalo, Roma produz a primeira carta aos Coríntios, por Clemente; o Pastor de Hermas, de um autor anônimo; vários textos de Justino mártir; além de receber pelo menos uma das cartas de Inácio de Antioquia e frear a produção literária dos seguidores de Marcião. Essa proporção maior entre os textos que sobreviveram deve-se, em parte, à capacidade de armazenamento e de produção dos textos com as suas cópias em uma capital imperial como Roma.

Outra característica a ser considerada é a pluralidade dos centros de agregação que essas obras representam. É consenso entre os estudiosos que a comunidade de Clemente, na via Labicana, e a escola de Justino, no complexo

${ }^{26}$ CLEMENT of Rome, 1 Clem. 56,2-15. 
termal próximo às Termas de Caracalla, desenvolvam os ministérios eclesiais de forma diferenciada. Na opinião de Knoch, no tempo de Clemente a necessidade de se promover a unidade dos diversos centros romanos de agregação nascia de um fenômeno interno que confirmava a existência de muitas comunidades particulares, onde umas conviviam em mútua abertura com as outras. Dessa forma, a iniciativa de corrigir a divisão da comunidade de Corinto era sustentada pela credibilidade de uma delegação enviada por Clemente a Corinto para testemunhar os avanços alcançados ao interno daquela cidade irmã que, apesar da diversidade de membros, ensinamentos e líderes, de alguma maneira conseguia superar as diferenças. ${ }^{27}$ Em contrapartida, há indícios que revelam que a realidade da igreja em Roma devia ser tão complexa que Justino pode não ter conhecido e pode não ter convivido com todos os contemporâneos que cita em suas obras. ${ }^{28}$

Ademais, de Clemente a Justino a liderança das comunidades sofre uma alteração considerável, sobretudo no que diz respeito à promoção dos ministérios secundários. Se em Clemente a autoridade e a responsabilidade de escrever alguma coisa são atribuições pertinentes ao ministério episcopal, em Justino o líder da comunidade cede a vez para o personagem que está fora do clero, mantendo o seu exercício debaixo da sua bênção e da sua chancela e criando novas oportunidades de diálogo com o mundo ao seu redor. Observamos, assim, de que maneira tudo isso junto concorra para melhor nos aproximar do uso dos textos das Escrituras na segunda metade do segundo século.

Em primeiro lugar os centros romanos de agregação cristã tinham verdadeiramente se tornado bibliotecas públicas de referência. No caso daquela comunidade específica de Justino, deve ter havido um investimento muito maior do que em outras comunidades para a aquisição e conservação dos livros. Era uma comunidade que ainda observava a dinâmica cristã da partilha dos bens, reservando uma parte para a ajuda aos mais pobres e outra parte para as necessidades comuns do grupo. ${ }^{29}$ Justino se refere ao que

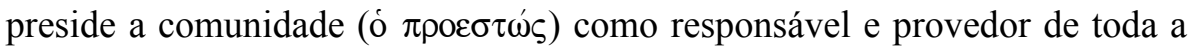
assistência caritativa que eles exerciam. ${ }^{30}$ Indiretamente encontramos aqui a indicação de reservas financeiras comuns para a manutenção, para a leitura e para a atividade reflexiva que resultava em maior compreensão dos livros

\footnotetext{
${ }^{27}$ KNOCH, O. B., In Namen des Petrus und Paulus, p. 36.

${ }^{28}$ SNYDER, H. G., Above the bath of Myrtinus, p. 336.

${ }^{29}$ JUSTINO de Roma, 1 Apol. 14, 2.

${ }^{30}$ JUSTINO de Roma, 1 Apol. 67, 6.
} 
sagrados. Bonner ressalta que não existia nada que pudesse deter um professor que quisesse abrir uma escola em Roma, tanto que esse fosse responsável financeiramente pela gestão da mesma. ${ }^{31}$ Por isso, as escolhas do líder da comunidade de Justino determinaram o processo de desenvolvimento que aquela comunidade viveu até ser amplamente reconhecida por causa dos seus livros e pela escola que havia criado. Segundo a lista dos autores bíblicos citados por Justino, a comunidade deu muita importância para os textos do Antigo Testamento, sobretudo o Pentateuco de Moisés, os salmos de Davi e os demais textos proféticos. Ali ainda havia uma coleção de textos cristãos que,

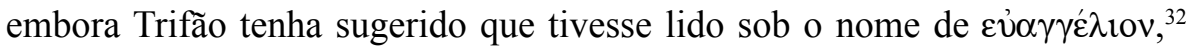

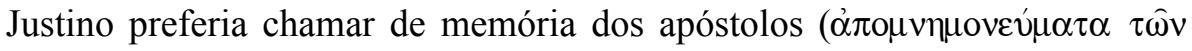
$\dot{\alpha} \pi 0 \sigma \tau o ́ \lambda \omega v) .{ }^{33}$ Outrossim, aparecem os livros da literatura pagã que, em certa ocasião, Justino chega a orgulhar-se de poder oferecer em sua comunidade, enquanto outras bibliotecas públicas do próprio Império voluntariamente impediam ao povo que tivesse acesso. ${ }^{34}$

Em segundo lugar, se a multiplicação das comunidades e o crescimento dos fiéis patrocinou os riscos de interpretações emancipadas e inovadoras, foi exatamente a garantia da catolicidade desses livros que permitia aos líderes cristãos comprovar a autoridade do seu ensinamento. Por catolicidade entende-se a necessidade de verificar se em outros lugares importantes como Antioquia, Alexandria, Cartago, Roma, Aquileia, Milão, Ravena e Lião havia o reconhecimento daquela obra. ${ }^{35}$ Nesse sentido, a troca de correspondência promovida por Clemente indicava que os textos citados por ele, inclusive o livro de Jó, em ambiente cristão precisavam ter passado por um reconhecimento de mútua aceitação e mútua confirmação, pelo menos entre as igrejas em Roma e em Corinto. Passadas algumas décadas, essas metrópoles aprendem a aprofundar o mecanismo de autopromoção através dos escritos que produzem, mantendo-se alertas seja à autoridade sagrada dos textos do Antigo Testamento, seja ao depósito da revelação que acredita ter sido transmitida por Cristo. $\mathrm{Na}$ época de Justino, Roma, mesmo através de uma comunidade secundária onde não se tinha a presença do líder principal daquela metrópole - definitivamente o "papa" não a frequentava - conseguiu expandir o seu network, na medida em

\footnotetext{
${ }^{31}$ BONNER, S. F., Education in ancient Rome, p. 47.

32 JUSTINO de Roma, Diál. 10, 2.

${ }^{33}$ JUSTINO de Roma, 1 Apol. 33, 5; Diál. 100, 4; Diál. 107, 1.

${ }^{34}$ JUSTINO de Roma, 1 Apol. 44, 12.

${ }^{35}$ GROSSI, V.; DI BERARDINO, A., La Chiesa antica, p. 22.
} 
que internamente ampliava o diálogo com os pagãos e externamente movia-se em diálogo com os judeus de Éfeso, onde aconteceu o encontro com Trifão. Note-se que Justino não entende que seja útil escrever sobre Jó nas Apologias, mas o faz exatamente no diálogo com Trifão.

Em terceiro e último lugar, a promoção de um líder que não fosse o epíscopo traz inúmeros benefícios para a literatura cristã e para o desenvolvimento teológico. Estamos diante do leigo que assume a tarefa de estudar, ensinar e resolver as questões relacionadas à interpretação bíblica. No início do Diálogo com Trifão, Justino experimentou um mal-estar em relação a alguns judeus que foram ríspidos e grosseiros consigo ao introduzir as primeiras questões do diálogo. Justino se sentiu tão chateado que resolveu se levantar para ir embora, mas Trifão insistiu que ele continuasse a apresentar as suas demonstrações doutrinais. ${ }^{36}$ Mais à frente, Trifão afirma que seguia com atenção aquilo que Justino dizia, pois tinha percebido que esse não apenas era competente, ${ }^{37}$ mas também recorria às várias Escrituras para comprovar as suas afirmações. ${ }^{38}$

Especificamente sobre Jó, não há muito espaço na obra de Justino, mas, nem por isso, essas informações deixam de ser valiosíssimas. Ocorre perceber que, durante o diálogo, Trifão menciona o texto de Jó e argumenta, segundo as explicações que conhecia, sobre qual seria o significado do texto que cita, não obstante o fato de não ter sido registrado o que concretamente ele teria dito. ${ }^{39}$ Isso significa que há uma hermenêutica alternativa de origem judaica que está se desenvolvendo em Éfeso, o que pelo menos impede-nos de pensar que o texto de Jó tinha se tornado insignificante nesse período.

Assim, com muito mais cuidado precisamos nos concentrar no texto de

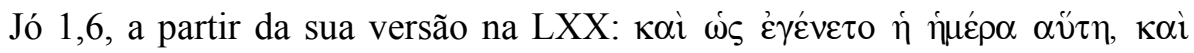

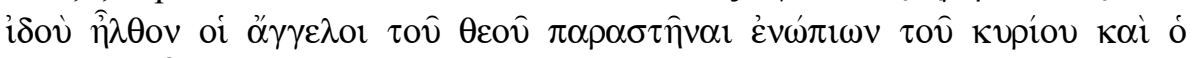

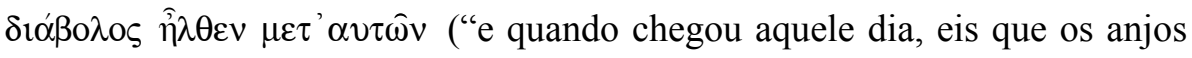
de Deus vieram para se colocar diante do Senhor e o diabo veio com eles"). Justino não cita a versão da LXX, mas transmite uma versão cujas variantes são testemunhadas somente no Diálogo com Trifão. ${ }^{40}$ Reparamos que há uma proposta clara de transformar o texto a partir de uma divisão isométrica em suas sílabas, conforme indicamos na seguinte tabela:

\footnotetext{
${ }^{36}$ JUSTINO de Roma, Diál. 9, 2.

${ }^{37}$ JUSTINO de Roma, Diál. 28, 1.

${ }^{38}$ JUSTINO de Roma, Diál. 80, 1.

${ }^{39}$ JUSTINO de Roma, Diál. 79, 4, no início da citação.

${ }^{40}$ JUSTINO de Roma, Diál. 79, 4, na metade da citação.
} 


\begin{tabular}{|c|c|c|c|c|c|c|c|c|c|c|c|c|c|}
\hline oi & $\stackrel{\pi}{\alpha} \gamma$ & $\gamma \varepsilon$ & $\lambda \mathrm{or}$ & $\hat{\eta} \lambda$ & $\theta$ ov & $\sigma \tau \hat{\eta}$ & $v \alpha \iota$ & $\varepsilon{ }^{\prime} \mu$ & $\pi \rho o$ & $\sigma \theta \varepsilon v$ & $\kappa v$ & $\rho i ́$ & ov \\
\hline$\kappa \alpha i$ & ó & $\delta 1$ & $\dot{\alpha}$ & $\beta o$ & $\lambda \mathrm{os}$ & $\ddot{\alpha}$ & $\mu \alpha$ & $\alpha v^{\prime}$ & $\tau$ ồ & $\dot{\varepsilon}$ & $\lambda \eta$ & $\lambda \dot{v}$ & $\theta \varepsilon \imath$ \\
\hline
\end{tabular}

Assim traduzimos a versão de Justino: os anjos vieram para estar na presença do Senhor e o diabo veio com eles. Curiosamente, a versão é metrificada, com os acentos no sétimo e no penúltimo pé, sendo que cada frase é completa em significado. A finalidade de tal métrica é obscura, pois o versículo em questão, era transmitido em prosa. De fato, o vocabulário do texto, mesmo sofrendo alteração na versão de Justino, depende da versão da

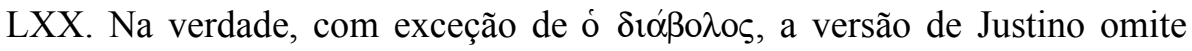
os principais elementos talmúdicos tradicionais. O versículo introduzia originalmente a vinda da assembleia celestial diante de Deus com הֵַ (um dia), pelo qual o Targum identificava a primeira parte da citação com o ano novo judaico e a segunda parte com o dia da expiação (Yom Kippur). ${ }^{41} \mathrm{Na}$ versão da

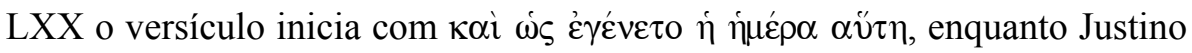
simplesmente não faz nenhuma alusão a isso. Entre a versão hebraica, a LXX e a versão apresentada por Justino a assembleia celestial é conceitualmente a

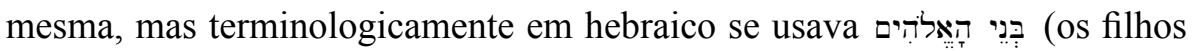
de Deus), conceito que o Targum já identificava com os seres celestiais ou os anjos que Deus tinha criado como os seus servos. ${ }^{42}$

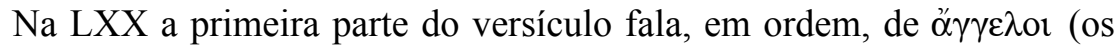
anjos), de $\theta$ cós (Deus) e de kúpıos (Senhor), enquanto a segunda parte faz

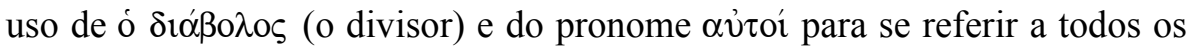
membros da corte celestial ou aos primeiros anjos que foram introduzidos naquela cena. Quanto mais claro for o ambiente cristão, maior será a tendência a observar a distinção entre $\theta \varepsilon o ́ s$ e кúpıos, isto é, entre o Pai e o Filho. Da mesma forma que, quanto mais judaizante for o ambiente cristão, maior a possibilidade desses termos serem um aposto, isto é, o kúpıos é $\theta$ cós vice-versa - a partir do qual o leitor se fixa no monoteísmo radical judaico.

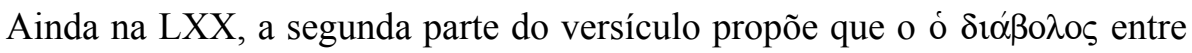
provavelmente no mesmo lugar onde estavam os outros personagens, dada a ambiguidade do pronome.

A versão de Justino sofre uma alteração considerável. A primeira parte do versículo introduz ó $\gamma \gamma \varepsilon \lambda o r$ como a LXX tinha feito, mas omite $\theta \varepsilon o ́ s$ para

\footnotetext{
${ }^{41}$ HARTLEY, J. E., The book of Job, p. 22.

${ }^{42}$ HARTLEY, J. E., The book of Job, p. 22.
} 
dizer que os outros personagens foram se reunir com kúpıs. Os motivos dessa alteração podem ser esclarecidos na própria exposição de Justino, como veremos em seguida. Ademais, a segunda parte também sofre interferências enormes, pela primeira vez testemunhadas entre os Padres da Igreja sobre

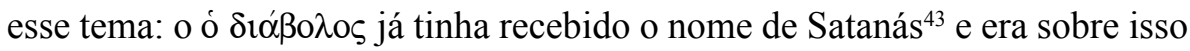

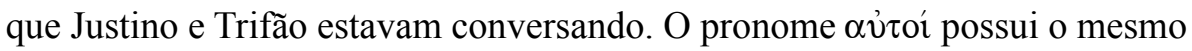
valor da versão da LXX.

Resta-nos, por enquanto, verificar qual o sentido que Justino dá à sua leitura de Jó 1,6. Acreditamos que seja um ensinamento que coincida com aquilo que os estudiosos costumam chamar de cristologia angélica, pela qual, de alguma maneira, os autores mais antigos da patrística associaram Cristo entre os personagens da corte celestial. ${ }^{44}$ É largo o arco de discussão entre Justino e Trifão sobre isso. Num determinado momento, Justino passa a explicar que o $\omega \varsigma$ vióv $\alpha \dot{v} \theta \rho \omega ́ \pi$ ov (semelhante ao filho do homem) de Dn 7,13 esclarece que, embora Cristo tenha aparecido e nascido como homem, ele não é de gérmen humano. ${ }^{45}$ Por esse motivo, Isaías $(9,5)$ o apresenta como $\mu \varepsilon \gamma \alpha \dot{\alpha} \lambda \eta \varsigma$

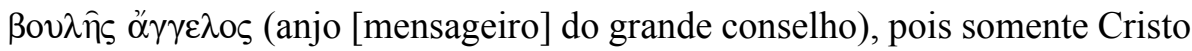
trouxe os conselhos de Deus para nós sem qualquer véu. ${ }^{46} \mathrm{E}$ continua:

Com efeito, se pelos profetas foi misteriosamente anunciado que Cristo devia vir de forma passível e depois alcançar o senhorio sobre todas as coisas, sem dúvida ninguém era capaz de entender isso, até que ele próprio persuadiu seus apóstolos que assim estava expressamente anunciado nas Escrituras. Com efeito, antes de ser crucificado, ele gritava: é preciso que $o$ Filho do Homem sofra muito, seja rejeitado pelos escribas e fariseus, seja crucificado e ressuscite no terceiro dia. E Davi proclamou que havia de nascer do ventre antes do sol e da lua, conforme o desígnio do Pai, e manifestou que, por ser Cristo, era Deus forte e admirável. ${ }^{47}$

A luta dos argumentos escriturísticos que Justino assume é travada para que ele possa convencer Trifão que Jesus faça parte da corte celestial. Nesse sentido, Trifão modificou o semblante do seu rosto, como se estivesse

\footnotetext{
${ }^{43}$ JUSTINO de Roma, Diál. 76,5.

${ }^{44}$ SIMONETTI, M., Studi sulla cristologia, p. 55.

${ }^{45}$ JUSTINO de Roma, Diál. 76,1.

${ }^{46}$ JUSTINO de Roma, Diál. 76,3.

${ }^{47}$ JUSTINO de Roma, Diál. 76,6-7.
} 
incomodado com aquilo que Justino estava falando e replicou, acusando-lhe de blasfêmia, por causa dos anjos que teriam se afastado de Deus. ${ }^{48}$ Nesse instante, Justino tenta evitar tensões e pede para que Deus dê a Trifão a mesma disposição pra com aquele sobre quem está escrito que os anjos servem. ${ }^{49}$ Justino está considerando a possibilidade de Trifão entender, a partir do título de Dn 7,13, que Cristo tem a mesma honra que o Pai. Assim, então, cita o texto de Jó.

A cristologia angélica em Justino torna-se ainda mais vivaz quando sugere que o anjo do Senhor que repreende Satanás em Zc 3,1-3 representa o próprio Cristo. ${ }^{50}$ Por isso, aceita a combinação entre o batismo no Jordão e a tentação no deserto como reflexo daquilo que tinha sido dito em Jó 1,6. Nesse sentido, diz:

Quando Jesus acabava de sair do rio Jordão e ouvia a voz que lhe dizia: "Tu és o meu Filho, eu hoje te gerei”, está escrito nas Memórias dos Apóstolos que o diabo, aproximando-se dele, o tentou até dizer-lhe: "Adora-me". A isso, Cristo retrucou: "Retira-te, Satanás. Adorarás ao Senhor teu Deus e somente a ele servirás". Do mesmo modo como conseguiu enganar Adão, se dizia que ele poderia lhe fazer algo. ${ }^{51}$

\section{Conclusão}

Antes da escola alexandrina do terceiro século estimular a produção de uma literatura sobre o livro de Jó, popularizando e ampliando a hermenêutica cristã sobre esse livro, somente em dois autores romanos encontramos a transmissão de algum aceno leve ao personagem ou ao seu conteúdo. Em comum, Clemente de Roma e Justino mártir exploram categorias da cristologia primitiva que passariam por desenvolvimentos ulteriores, mas revelavam que, naquele contexto cristão romano, não havia mais embaraço de introduzir o Cristo nas suas explicações sobre Jó. Clemente é o primeiro Padre da Igreja a fornecer as informações sobre Jó, de quem é capaz de transmitir mais conteúdo que Justino. Clemente não permite que criemos uma ideia falsa como se o texto de Jó não tivesse credibilidade, nem fosse

\footnotetext{
${ }^{48}$ JUSTINO de Roma, Diál. 79,1.

49 JUSTINO de Roma, Diál. 79,2.

${ }^{50}$ JUSTINO de Roma, Diál. 103, 6; 79, 1-4.

${ }^{51}$ JUSTINO de Roma, Diál. 103, 6.
} 
conhecido entre os cristãos, na medida em que o valoriza e o compara em renome com Moisés e Davi. Ao recuperar a teologia paulina da primeira carta aos Coríntios, Clemente assume o testemunho de Jó como válido para que os servos orgulhosos de Corinto se arrependam em vista do prêmio que os justos recebem, quando obedecem a Deus. Cita Jó para defender o universalismo do pecado entre os homens e traça, em consequência, a dinâmica pela qual a fênix, renovada em seu ninho, se tornou modelo para a ressurreição de Cristo e de todos os que servem a Deus.

Embora haja pouquíssima referência de Jó em Justino, concluímos que Jó 1,6, como os demais textos do Antigo Testamento citados em suas obras, tenha passado pela reflexão da Igreja romana motivada pelos seus líderes ao promover também os seus leigos na tarefa de refletir sobre a fé. $\mathrm{O}$ núcleo central da cristologia angélica continua sendo apresentado a partir do significado do título "Filho do Homem" de Dn 7,13, que, em última análise, transmite o conceito da origem divina de Cristo. Por uma versão revisada a partir da LXX, Justino menciona o protagonismo de Cristo na cena da corte celestial, propondo que a descrição do texto de Jó 1,6 tenha se repetido entre o Batismo de Cristo no Jordão e a tentação no deserto.

\section{Referências bibliográficas}

AGOSTINO. Perfezione della giustizia dell'uomo. Roma: Editrice Città Nuova, 1987. (Opera Omnia, XVII/1).

BISHOP, W. W. Roman Church Mosaics of the First Nine Centuries with Especial Regard to Their Position in the Churches. American Journal of Archeology, v. 10, n. 3, p. 251-281. Disponível em: <https://www.jstor.org/ stable/496981?seq=13\#metadata_info_tab_contents $>$. Acesso em: 10 abr. 2020.

BOBICHON, Ph. Justin Martyr, Dialogue avec Triphon. Fribourg: Academic Press Fribourg, 2003.

BONNER, S. F. Education in ancient Rome: from the elder Cato to the younger Pliny. California: California University Press, 1977.

CARNEVALE, L. Giobbe: Dall'antichità al medioevo. Testi, tradizioni, immagini. Bari: Edipulia, 2010.

GROSSI, V.; DI BERARDINO, A. La Chiesa antica: ecclesiologia e 
istituzioni. Roma: Edizioni Borla, 1984.

HARTLEY, J. E. The book of Job. Grand Rapids: William B. Eerdmans Publishing Company, 1988.

HOLMES, W. R.; METZGER, B. M. The Apostolic Fathers. Greek texts and English Translations. Grand Rapids: Baker Academic, 2007.

JUSTINO de Roma. I e II Apologias; Diálogo com Trifão. São Paulo: Paulus, 1995.

KNOCH, O. B. In Namen des Petrus und Paulus. Der Brief des Clemens Romanus und die Eigenart des römischen Christentums. Aufstieg und Niedergang der römischen Welt, v. 27, n. 1, p. 3-54, 1993.

MARA, M. G. Giobbe. In: DI BERARDINO, A. (Ed.). Nuovo Dizionario Patristico e di Antichità Cristiane. Genova-Milano: Casa Editrice Marietti, 2007. p. 2158-2160.

MUNIER, Ch. Justin, Apologie pour les Chrétiens. Introduction, texte, traduction et notes. Paris: Sources Chrétiennes, 2006.

NIGG, J. Transformations of the Phoenix: from the Church Fathers to the Bestiaries. IKON Journal of Iconography Studies, v. 2, p. 93-102, 2009. Disponível em: <https://www.brepolsonline.net/doi/pdf/10.1484/J. IKON.3.33>. Acesso em: 08 abr. 2020.

NOVA VULGATA: Bibliorum sacrorum editio. Città del Vaticano: Libreria Editrice Vaticana, 1999.

PORTER, S. E.; LAND, C. D. Paul and Scripture. Leiden-Boston: Brill, 2019. (Pauline Studies, 10).

SEPTUAGINT. Revised Edition. Stuttgart: Deutsche Bibelgesellschaft, 2006.

SIMONETTI, M. Il cristianesimo antico. In: VIAN, G. M. Storia del cristianesimo: bilanci e questioni aperte: atti del Seminario per il cinquecentesimo del Pontificio comitato di scienze storiche. Città del Vaticano: Libreria Editrice Vaticana, 2005.

SIMONETTI, M. Studi sulla cristologia del II e III secolo. Roma: Institutum Patristicum Augutianianum, SEA 44, 1993.

SNYDER, H. G. Above the bath of Myrtinus: Justin Martyr's in the city of Rome. Harvard Theological Review, v. 100, n. 3, p. 335-362, 2007. 
TREMBLAY, H. Job 19, 25-27 dans la Septante et chez les Pères grecs. Unanimité d'une tradition. Paris: J. Gabalda, 2002.

ZIEGLER, J. Iob 14,4-5a als wichtigster Schriftbeweis für die These "Neminem sine sorde et sine peccato esse" (Cyprian, Test 3,54), bei lateinischen christlichen Schriftstellen. Sitzungsberichte der Bayerischen Akademie der Wissenschaften, h. 3, p. 1-43, 1985.

André Luiz Rodrigues da Silva

Doutor em Ciência e Teologia Patrística pelo Institutum Patristicum Augustinianum, Roma Docente do Programa de Pós-graduação em Teologia da Pontifícia Universidade Católica do Rio de Janeiro Rio de Janeiro / RJ - Brasil E-mail: leleur@yahoo.it

Recebido em: $14 / 04 / 20$ Aprovado em: 28/05/20 